\title{
Adubação orgânica e inorgânica de batatinha em solos arenosos: Produtividade, nutrientes na planta e lixiviação
}

\author{
Fabio F. de Oliveira ${ }^{1}$, Ignacio H. Salcedo ${ }^{1}$ \& Sandra R. S. Galvão ${ }^{1}$
}

\begin{abstract}
RESUMO
As relações entre os teores de nutrientes em solos com adubação orgânica e inorgânica e os teores de nutrientes e produtividade de batatinha foram determinadas tal como as relações entre aportes e a lixiviação de $\mathrm{N}$ e bases trocáveis. Amostras de solo foram coletadas das camadas de 0-20, 20-40 e 40$60 \mathrm{~cm}$ em 18 áreas de produção com adições anuais de esterco variando entre 2 e 40 anos e, como controle, quatro áreas sob pastagem não adubadas. Amostras de solo e planta foram analisadas quanto aos teores de N, P, K, Ca e Mg. A produtividade de tubérculo com padrão comercial apresentou relação positiva com a quantidade de $\mathrm{N}$ aplicada e a produtividade total indicou relação com o estoque de $\mathrm{N}$ do solo; somente o Ca no solo se correlacionou com os teores na planta mas não com a produtividade. As bases trocáveis aumentaram nas três camadas, de acordo com o aumento do esterco aplicado enquanto no $\mathrm{N}$ total o aumento só ocorreu nas camadas de 0-20 e 20-40 cm; por fim, a translocação de nutrientes para camadas mais profundas representa prejuízo econômico e provável risco ambiental.
\end{abstract}

Palavras-chave: Solanum tuberosum, esterco, lixiviação

\section{Organic and inorganic fertilization of potato in sandy soils: Productivity, nutrients in the plant and leaching}

\begin{abstract}
The relationships between the nutrient content in soils fertilized with organic and inorganic sources, and the nutrient contents and productivities of potato as well as the relationships of applications and the leaching of $\mathrm{N}$ and exchangeable bases were determined. Soil samples were collected from the 0-20, 2040 and $40-60 \mathrm{~cm}$ layers in 18 areas of potato production receiving annual applications of farm yard manure for the last 2 to 40 years and, as control, four areas under non-fertilized pasture. Soil and plant samples were analysed for $\mathrm{N}, \mathrm{P}, \mathrm{K}, \mathrm{Ca}$ and $\mathrm{Mg}$ concentrations. The yield of large tubers had a positive relationship with the input of $\mathrm{N}$ while total yields related with total soil $\mathrm{N}$. Only $\mathrm{Ca}$ in the soil correlated with the levels in the plant, but not with productivity. Exchangeable bases increased in the three layers following increases in applied manure, while total soil $\mathrm{N}$ increased only in the 0-20 and 20-40 cm layers. The translocation of nutrients to deeper layers represents economic loss and possible environmental risk.
\end{abstract}

Key words: Solanum tuberosum, manure, lixiviation 


\section{INTRODUÇÃO}

A mesorregião do Brejo Paraibano tem peculiaridades climáticas bem distintas na maior parte do Nordeste, com temperaturas amenas e alto índice pluviométrico, durante alguns meses do ano; essas particularidades são responsáveis pela entrada da bataticultura na região. O município de Esperança é o principal centro de produção, sobressaindo-se a batatinha e a erva doce como as culturas que oferecem maior viabilidade econômica (Sabourin et al., 2000).

Os solos utilizados para produção de batatinha são, em quase sua totalidade, classificados como Neossolos Regolíticos, muito arenosos e com baixa fertilidade natural, carecem de aplicação de adubo para alcançar produções satisfatórias. Como os produtores são descapitalizados, isto é, sem condiçõos de adquirir as quantidades necessárias de fertilizantes, a adubação se limita quase sempre à aplicação de esterco bovino e, ocasionalmente, como fertilizante nitrogenado (Galvão et al., 2008).

Além de fonte de nutrientes o esterco é a fonte principal de aportes de matéria orgânica nas áreas de produção de batatinha ou de culturas de subsistência, no agreste e no semiárido nordestino (Menezes \& Salcedo, 2007) com aplicação média anual de $16 \mathrm{t} \mathrm{ha}^{-1}$. O esterco é utilizado de forma empírica, ocorrendo normalmente adição de quantidades muito elevadas que podem resultar em acúmulo de $\mathrm{P}$ e de outros nutrientes na superfície do solo (Sharpley et al., 2004; Silva et al., 2007; Galvão \& Salcedo, 2009), deslocamento para camadas mais profundas (Galvão et al., 2008) e perda de nutrientes (Siddique et al., 2000; Akhtar et al., 2005).

Normalmente, a entrada de $\mathrm{P}$ via esterco excede as exigências das culturas tendo em vista que a dose aplicada se baseia na necessidade de N (Akhtar et al., 2005) e que a planta absorve em uma relação N/P muito mais ampla que a relação encontrada nos estercos. Por este motivo, o P disponível até $60 \mathrm{~cm}$ de profundidade nesses solos apresentou acréscimo em mais de 20 vezes em relação às áreas testemunhas de pastagem que não recebiam esterco, além de acréscimos significativos no conteúdo de P total (Galvão et al., 2008; Galvão \& Salcedo., 2009).

Por se tratar de região com solos de características relativamente homogêneas, com predomínio da fração areia e muito deficientes em $\mathrm{P}$ quando não adubados e, ainda, em virtude de ser um nutriente relativamente pouco móvel, Galvão et al. (2008) interpretaram os acréscimos em Ptot em relação às áreas não adubadas, como o histórico da aplicação acumulada de esterco ao longo do tempo, em cada área, em termos de quantidades adicionadas. Juntamente com os aumentos de Ptot, também foram observados aumentos em nitrogênio orgânico total (Ntot) e bases trocáveis (Galvão et al., 2008); entretanto, os autores não avaliaram a relação entre os aumentos de nutrientes no solo e a produtividade da batatinha nas áreas amostradas.

A acumulação de nutrientes no solo consistiu, além das necessidades das culturas, um cenário preocupante, tanto do ponto de vista econômico, por ser o esterco um insumo limitado e muitas vezes obtido externamente à propriedade (Garrido et al., 2008), quanto do ambiental, por conta da possibilidade de poluição dos reservatórios de água das propriedades rurais e do aumento da emissão de $\mathrm{CO}_{2}$.

Por esta razão, o primeiro objetivo do presente trabalho foi estudar a relação entre as acumulações de nutrientes em áreas de cultivo de batatinha, por conta da adição excessiva de esterco e a produtividades da cultura, enquanto a segunda meta foi avaliar o efeito dessas adições no deslocamento em profundidade das bases trocáveis e do Ntot.

\section{Material e MÉTOdos}

As propriedades de agricultura familiar selecionadas para a amostragem estavam distribuídas no município de Esperança, no Agreste da Paraíba, localizadas entre as latitudes $6^{\circ} 58^{\prime} 08^{\prime \prime}$

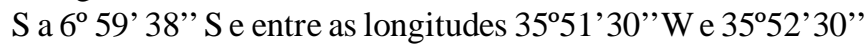
W. Nessas propriedades há pequenas áreas cultivadas com batatinha (Solanum tuberosum L.) e erva-doce (Pimpinella anisum L.) consorciadas, consideradas cultivos mercantis da região, além de roçados tradicionais de milho (Zea mays L.), feijão mulatinho (Phaseolus vulgaris L.), feijão de corda (Vigna unguiculata L.), mandioca (Manihot esculenta Crantz) e fava (Vicia faba L.) (Sabourin et al., 2000). O solo dominante nas áreas amostradas é o Neossolo Regolítico eutrófico (EMBRAPA, 1997), de textura arenosa a franco-arenosa com relevo ondulado a suave-ondulado. A pluviosidade média anual é de $800 \mathrm{~mm}$ com regime de chuvas unimodal distribuídas entre os meses de março a agosto, embora tanto a média anual quanto sua distribuição possam ser bastante variáveis (Sabourin et al., 2000).

Para atender ao primeiro objetivo foram amostradas 12 áreas que se encontravam com cultivo de batatinha consorciada com erva-doce enquanto para o segundo objetivo se amostraram, além dessas áreas, seis áreas adicionais que, por ocasião da amostragem, estavam em pousio, mas eram áreas de lavoura de batatinha solteira e tinham sido adubadas com esterco.

Pelos históricos levantados junto aos produtores, dentre as18 áreas 14 foram adubadas entre 15 e 40 anos e quatro durante menos de seis anos. As quantidades anuais de esterco curtido aplicadas variaram entre 4 e $28 \mathrm{t} \mathrm{ha}^{-1}$. O esterco utilizado apresentou a seguinte composição química: 1,0\% de N, 0,3\% de $\mathrm{P}$ e $1,0 \% \mathrm{~K}$, com $85 \%$ de matéria seca (valores médios de nove amostras coletadas com os produtores), Galvão et al., 2008. Para atuarem como testemunha em relação ao segundo objetivo também foram amostradas quatro áreas com pastagens, que não haviam sido adubadas nos últimos 10 anos.

Em cada área foram coletadas 10 amostras simples de 0-20, 20-40 e 40-60 cm de profundidade, nas linhas de plantio, em transecto cruzando a área. Nas áreas em pousio ou com pastagem retiraram-se 10 amostras simples a intervalos regulares ao longo de um transecto, também abrangendo a área toda. A partir das amostras simples foi constituída uma amostra composta por área e por camada de solo. Nas amostras compostas de solo foram determinados o pH em água (1:2,5), os teores de $\mathrm{P}$ e K extraíveis com Mehlich-1 e quantificados por colorimetria e fotometria de chama, respectivamente. Os teores de Ca e Mg trocáveis foram extraídos com $\mathrm{KCl} 1 \mathrm{~mol} \mathrm{~L}^{-1} \mathrm{e}$ quantificados por espectrofotometria de absorção atômica 
(EMBRAPA, 1997). Uma subamostra foi passada em peneira de 0,015 mm para análise de Carbono orgânico total (COT) por oxidação úmida (EMBRAPA, 1997) Nitrogênio total (Ntot) pelo método de Kjeldahl por destilação com arraste a vapor (Bremner \& Mulvaney, 1982). O Fósforo total (Ptot) foi quantificado após digestão com uma mistura de $\mathrm{H}_{2} \mathrm{SO}_{4}$ concentrada e $\mathrm{H}_{2} \mathrm{O}_{2}$, por colorimetria.

Nas 12 áreas que se encontravam com cultivo de batatinha durante a amostragem de solo foram amostrados folíolos 60 dias após plantio, para determinação dos teores de nutrientes. Os folíolos foram coletados do terço médio da planta, que foram secadas em estufa de circulação de ar forçada a $60{ }^{\circ} \mathrm{C}$, moídos e digeridos com uma mistura de $\mathrm{H}_{2} \mathrm{SO}_{4}$ concentrado e $\mathrm{H}_{2} \mathrm{O}_{2}$ (Thomas et al., 1967) para determinação dos teores totais de N, $\mathrm{P}, \mathrm{K}, \mathrm{Ca}$ e Mg. Após digestão as metodologias de análise foram as mesmas usadas para amostras de solo. A produtividade da batatinha foi acompanhada na fase de colheita. A batata colhida foi separada em duas classes, uma de tamanho comercial $(\varnothing>8$ $\mathrm{cm}$ ) e outra de tubérculos pequenos, de acordo com a seleção efetuada pelos produtores.

Os teores de $\mathrm{P}$ total na profundidade de $0-20 \mathrm{~cm}$ foram utilizados como base para fazer inferências sobre os demais nutrientes em virtude da sua menor mobilidade, baixos teores em áreas sem aplicação de esterco (Galvão et al., 2008) e pelo fato do ,esterco ser a única fonte externa desse elemento. Para isto, ditos teores foram divididos em quatro faixas, sendo a faixa 1 (Ptot $<110 \mathrm{mg} \mathrm{kg}^{-1}$ ) constituída das quatro áreas não adubadas enquanto entre as dubadas nove ficaram distribuídas na faixa 2 (Ptot $\left.=111-220 \mathrm{mg} \mathrm{kg}^{-1}\right)$, cinco na faixa 3 (Ptot $=221-$ $330 \mathrm{mg} \mathrm{kg}^{-1}$ ) e quatro na faixa 4 (Ptot $\left.=331-440 \mathrm{mg} \mathrm{kg}^{-1}\right) . \mathrm{O}$ motivo para esta divisão por faixas foi tentar visualizar qual a relação entre doses crescentes de esterco acumuladas ao longo do tempo na camada de 0-20 cm, e o comportamento do Ntot e bases trocáveis na camada de 0-20, 20-40 e 40-60 cm, o que não seria possível caso se adotasse apenas o teste-t de Student para amostras adubadas versus não adubadas.

A relação entre os diversos atributos de solo e planta e da produtividade foi avaliada por análise de regressão. As diferenças entre as quatro faixas de Ptot na profundidade de 0$20 \mathrm{~cm}$ em relação aos teores de N, K, Ca e Mg, nas camadas de 0-20, 20-40 e 40-60 cm, foram submetidas à análise de variância para cada profundidade e as médias comparadas pelo teste HSD Tukey, a $5 \%$ de probabilidade, para número desigual de repetições.

\section{RESULTADOS E DISCUSSÃO}

A análise química de amostras de solo coletadas de 0-20 cm, revelou altos níveis de $\mathrm{P}, \mathrm{K}, \mathrm{Ca}$ e $\mathrm{Mg}$ na maioria das áreas cultivadas (Tabela 1). O carbono total (Ctot) e o Ntot do solo tiveram acréscimo de mais de $100 \%$ em algumas áreas que vinham recebendo esterco, comparadas com áreas de pastagem sem uso de esterco, coincidindo com trabalhos que mostraram incremento na MOS em áreas com utilização de esterco e/ou outros resíduos orgânicos (Erich et al., 2002; Mitchell \& Tu, 2006; Silva et al., 2007; Galvão et al., 2008) e, consequentemente, melhorias nas propriedades químicas, físicas e biológicas do solo (Bayer \& Mielnikzuc, 1999). Em comparação com as áreas não adubadas com esterco, o aumento no Ctot foi significativo; no entanto, as amostras apresentaram níveis considerados baixos, próximos a $10 \mathrm{~g} \mathrm{~kg}^{-1}$.

A produtividade total da batatinha foi muito baixa na área 9 $\left(1,87 \mathrm{t} \mathrm{ha}^{-1}\right)$ e alta $\left(>10 \mathrm{t} \mathrm{ha}^{-1}\right)$ nas áreas $1 \mathrm{e} 7$, levando-se em consideração a média atual da região de $8 \mathrm{t} \mathrm{ha}^{-1}$ (Tabela 2). Por se tratar de áreas com características pedológicas e históricos de uso similares, esta variação foi atribuída à heterogeneidade nas quantidades de adubo solúvel e esterco aplicados ao longo

Tabela 1. Atributos de amostras de solo coletadas de $0-20 \mathrm{~cm}$ em 22 áreas de produção de batatinha, adubadas com esterco e em áreas de pastagem sem uso de esterco

\begin{tabular}{|c|c|c|c|c|c|c|c|c|c|}
\hline \multirow{2}{*}{ Área } & \multirow{2}{*}{ Cultivo } & \multirow{2}{*}{ Adubação esterco } & Ptot & Ntot & Ctot & \multirow{2}{*}{$\begin{array}{l}\text { PMelich } \\
\mathrm{mg} \mathrm{kg}^{-1}\end{array}$} & $\mathbf{K}$ & $\mathrm{Ca}$ & $\mathrm{Mg}$ \\
\hline & & & & $\mathrm{g} \mathrm{kg}^{-1}$ & & & \multicolumn{3}{|c|}{$\mathrm{cmol}_{\mathrm{c}} \mathrm{kg}^{-1}$} \\
\hline 1 & Pastagem & não & 67 & 0,25 & 2,7 & 2,8 & 0,34 & 0,47 & 0,17 \\
\hline 2 & Pastagem & não & 110 & 0,46 & 5,9 & 8,3 & 0,12 & 0,89 & 0,25 \\
\hline 3 & Pastagem & não & 78 & 0,29 & 3,2 & 1,4 & 0,20 & 0,70 & 0,23 \\
\hline 4 & Pastagem & não & 88 & 0,30 & 3,7 & 2,5 & 0,14 & 0,73 & 0,27 \\
\hline 5 & Pousio & $\operatorname{sim}$ & 173 & 0,54 & 5,9 & 45,0 & 0,35 & 1,62 & 0,81 \\
\hline 6 & Pousio & $\operatorname{sim}$ & 171 & 0,49 & 4,9 & 75,0 & 0,37 & 1,82 & 0,60 \\
\hline 7 & Batata & $\operatorname{sim}$ & 212 & 0,53 & 5,9 & 72,0 & 0,24 & 2,19 & 0,91 \\
\hline 8 & Batata & $\operatorname{sim}$ & 182 & 0,55 & 5,8 & 37,0 & 0,15 & 1,70 & 0,76 \\
\hline 9 & Pousio & $\operatorname{sim}$ & 194 & 0,46 & 5,0 & 47,0 & 0,17 & 1,92 & 0,48 \\
\hline 10 & Pousio & sim & 203 & 0,63 & 6,5 & 35,0 & 0,21 & 2,12 & 0,81 \\
\hline 11 & Pousio & $\operatorname{sim}$ & 127 & 0,53 & 5,3 & 20,0 & 0,10 & 1,55 & 0,36 \\
\hline 12 & Pousio & $\operatorname{sim}$ & 216 & 0,54 & 6,2 & 49,0 & 0,44 & 2,21 & 0,59 \\
\hline 13 & Batata & $\operatorname{sim}$ & 176 & 0,70 & 8,5 & 167,0 & 0,39 & 1,96 & 0,83 \\
\hline 14 & Batata & sim & 231 & 1,12 & 6,2 & 47,0 & 0,29 & 1,87 & 0,88 \\
\hline 15 & Batata & $\operatorname{sim}$ & 302 & 1,20 & 9,4 & 117,0 & 0,39 & 1,78 & 0,69 \\
\hline 16 & Batata & $\operatorname{sim}$ & 287 & 1,04 & 12,4 & 74,0 & 0,45 & 1,51 & 0,72 \\
\hline 17 & Batata & $\operatorname{sim}$ & 258 & 0,92 & 10,9 & 76,0 & 0,30 & 1,54 & 0,77 \\
\hline 18 & Batata & $\operatorname{sim}$ & 279 & 1,33 & 9,8 & 96,0 & 0,56 & 1,70 & 0,61 \\
\hline 19 & Batata & $\operatorname{sim}$ & 393 & 0,63 & 6,3 & 139,0 & 0,18 & 2,34 & 1,12 \\
\hline 20 & Batata & $\operatorname{sim}$ & 341 & 0,85 & 8,1 & 62,0 & 0,33 & 1,57 & 0,75 \\
\hline 21 & Batata & sim & 351 & 0,95 & 11,4 & 187,0 & 0,61 & 2,02 & 0,99 \\
\hline 22 & Batata & $\operatorname{sim}$ & 354 & 1,15 & 8,8 & 85,0 & 0,43 & 1,21 & 0,44 \\
\hline
\end{tabular}


do tempo, pois na área 9 a aplicação de esterco nos últimos 4 anos foi, em média, 4 t ha ${ }^{-1}$ e sem nenhuma adição de $\mathrm{N}$ mineral por ocasião do plantio da batatinha, segundo os produtores nessas áreas. Coincidentemente, os teores de $\mathrm{N}$ e $\mathrm{P}$ do folíolo na área 9 foram os menores de todas as áreas mas não no caso de $\mathrm{K}, \mathrm{Ca}$ e $\mathrm{Mg}$.

Tabela 2. Produtividade de tubérculos frescos e composição química do folíolo da batatinha em 12 áreas

\begin{tabular}{|c|c|c|c|c|c|c|}
\hline \multirow{2}{*}{ Área } & $\mathbf{N}$ & $\mathbf{P}$ & $\bar{K}$ & $\mathrm{Ca}$ & $\mathrm{Mg}$ & \multirow{2}{*}{$\begin{array}{l}\text { Produtividade } \\
\qquad \text { ha }^{-1}\end{array}$} \\
\hline & \multicolumn{5}{|c|}{$\mathrm{g} \mathrm{kg}^{-1}$} & \\
\hline 1 & 39 & 4,2 & 65 & 26 & 6,3 & 10,5 \\
\hline 2 & 44 & 2,6 & 41 & 20 & 8,6 & 2,9 \\
\hline 3 & 52 & 4,5 & 48 & 18 & 6,3 & 3,9 \\
\hline 4 & 48 & 4,4 & 53 & 14 & 5,6 & 4,3 \\
\hline 5 & 41 & 2,8 & 47 & 31 & 8,6 & 4,4 \\
\hline 6 & 50 & 2,7 & 66 & 27 & 9,4 & 5,9 \\
\hline 7 & 34 & 4,3 & 45 & 33 & 9,6 & 10,6 \\
\hline 8 & 38 & 2,7 & 47 & 39 & 8,6 & 6,8 \\
\hline 9 & 32 & 2,1 & 49 & 34 & 7,8 & 1,9 \\
\hline 10 & 39 & 3,8 & 55 & 26 & 9,5 & 9,1 \\
\hline 11 & 44 & 3,1 & 38 & 30 & 9,6 & 8,1 \\
\hline 12 & 39 & 2,6 & 43 & 31 & 8,7 & 6,9 \\
\hline
\end{tabular}

A produtividade total se relacionou significativamente $(\mathrm{p}<$ $0,01)$ com os estoques de Ntot no solo, que variaram entre 1700 e $3600 \mathrm{~kg} \mathrm{ha}^{-1}$ de solo na camada de $0-20 \mathrm{~cm}$ (Figura 1) sendo que o valor inferior foi apresentado na área 9, com a menor aplicação de esterco, como já relatado.

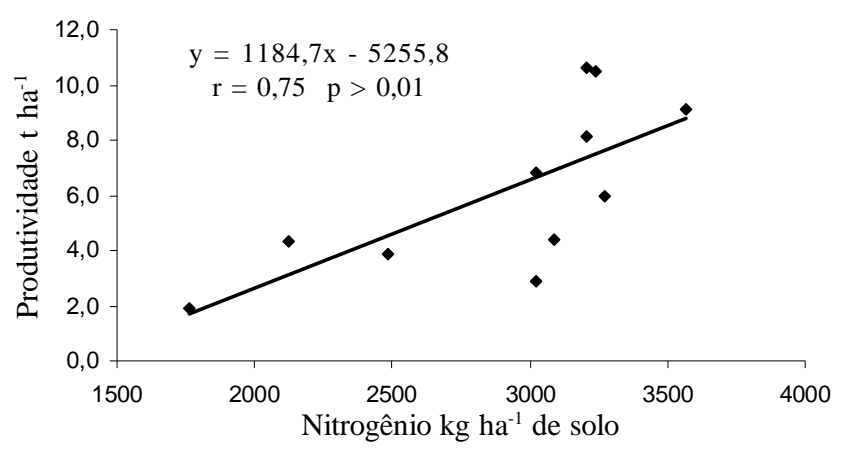

Figura 1. Relação entre estoque de N no solo e a produção total de tubérculos de batatinha (Safra 2005)

$\mathrm{O}$ teor de $\mathrm{N}$ no tecido vegetal variou de 32 a $52 \mathrm{~g} \mathrm{~kg}^{-1}$ de matéria seca (Tabela 2) e não teve correlação com qualquer parâmetro no solo. A faixa de referência para condições ideais de nutrição da batatinha, descrita por Cantarutti et al. (2007), é de 45 a $60 \mathrm{~g} \mathrm{~kg}^{-1}$, sendo que somente metade das áreas apresentou teores dentro desta faixa indicando que o manejo do $\mathrm{N}$ nas demais áreas não está atendendo à necessidade da cultura podendo estar ocorrendo falta desse nutriente no início do ciclo da cultura devido à provável imobilização de $\mathrm{N}$ na fase inicial, pela adição do esterco. Silva et al. (2007) observaram aumento na disponibilidade de $\mathrm{N}$ em solo similar adubado com esterco apenas após 60 dias de aplicação.

A produção de tubérculos com padrão comercial (batata grande) foi influenciada positivamente $(r=0,75, \mathrm{p}<0,01)$ pela quantidade de $\mathrm{N}$ aplicada (Figura 2). Esta relação foi significativa apenas quando se considerou o somatório do aporte de $\mathrm{N}$ do esterco mais o $\mathrm{N}$ do adubo solúvel aplicado no plantio, que variou de 46 a $277 \mathrm{~kg} \mathrm{ha}^{-1}$ (Figura 2). Uma vez que a dose de esterco é, em média, $16 \mathrm{t} \mathrm{ha}^{-1}$ e com pequena amplitude entre áreas, a relação significativa sugere que a aplicação isolada de esterco não supre a demanda por $\mathrm{N}$ pela batatinha e que o suplemento do adubo solúvel nessas áreas foi essencial para as melhores produtividades. Por outro lado, é provável que altas entradas de $\mathrm{N}$ conduzam a perdas desse nutriente, visto que em algumas propriedades foram fornecidos quase $300 \mathrm{~kg} \mathrm{ha}^{-1}$ para uma retirada estimada em torno de 100 $\mathrm{kg} \mathrm{ha}^{-1}$ (Galvão et al., 2008), e o desbalanço entre entradas e saídas não se traduz no correspondente aumento do estoque de N no solo.

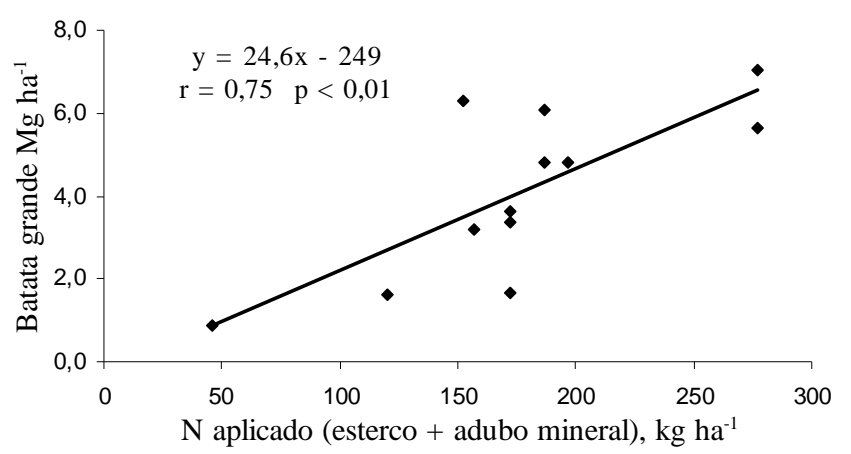

Figura 2. Relação entre a quantidade de $\mathrm{N}$ aplicada (esterco + adubo solúvel) e produtividade de tubérculos de batatinha com padrão comercial

Quando se analisa o histórico de longo prazo, o efeito benéfico das adições de esterco é evidente pela correlação positiva entre teores de $\mathrm{N}$ no solo e aumento de produtividade. Por outro lado, quando se avalia a produção baseada na aplicação do último ano, percebe-se que não há relação entre a dose de esterco e a produção, sendo necessário, por este motivo, incluir aportes de $\mathrm{N}$ de fontes solúveis.

A velocidade de decomposição do esterco e a consequente liberação de $\mathrm{N}$ e outros nutrientes, são muito variáveis e dependentes de diversos fatores intrínsecos ao esterco e às condições de clima e solo (Eghball, 2000; Griffin \& Honeycutt, 2000), podendo não ocorrer sincronia com a demanda da planta; assim, aplicações de quantidades excessivas dessa fonte podem resultar em risco ambiental, além de prejuízo econômico.

A alternativa pode ser a utilização de menores quantidades de esterco com uma fonte de $\mathrm{N}$ mais lábil, seja adubo mineral ou um resíduo com relação $\mathrm{C} / \mathrm{N}$ mais estreita, podendo disponibilizar nitrogênio de forma mais sincronizada com a necessidade da planta e evitando grandes aportes dos demais nutrientes.

Em todas as áreas os teores de P e K extraíveis (Tabela 1) estiveram, em média, acima dos valores considerados altos para esses nutrientes (EMATER-PB, 1979), > $30 \mathrm{mg} \mathrm{kg}^{-1} \mathrm{de}$ solo para o $\mathrm{Pe}>117 \mathrm{mg} \mathrm{kg}^{-1}$ para o $\mathrm{K}$, motivo por que ambos não apresentaram relação com a produtividade nem com os teores determinados na planta. Os teores de $\mathrm{P}$ na planta variaram entre $2 \mathrm{e} 4 \mathrm{~g} \mathrm{~kg}^{-1}$ enquanto os de $\mathrm{K}$ oscilaram entre $38 \mathrm{e} 65 \mathrm{~g} \mathrm{~kg}^{-1}$. De acordo com as faixas consideradas ideais para batatinha, 
os teores no folíolo de P (Cantarutti et al., 2007) e K (Cogo et al., 2006) estão em níveis adequados.

Os teores de Ca e $\mathrm{Mg}$ no solo foram altos, acima de $2 \mathrm{cmol}_{\mathrm{c}}$ $\mathrm{kg}^{-1}$ para o somatório de $\mathrm{Ca}$ e $\mathrm{Mg}$, quando o manual de adubação indica valores acima de $1 \mathrm{cmol}_{\mathrm{c}} \mathrm{kg}^{-1}$, como sendo altos (EMATER-PB, 1979). Como indicado anteriormente, esses teores elevados, assim como os de $\mathrm{P}$ e K, estão associados à aplicação contínua de esterco, ao longo dos anos. Os teores de Ca na planta apresentaram correlação com os teores no solo (Figura 3); apesar disto, não tiveram relação com os valores de produtividade, sugerindo consumo de luxo pela cultura; já o $\mathrm{Mg}$ na planta não apresentou correlação com os teores no solo nem com a produtividade.

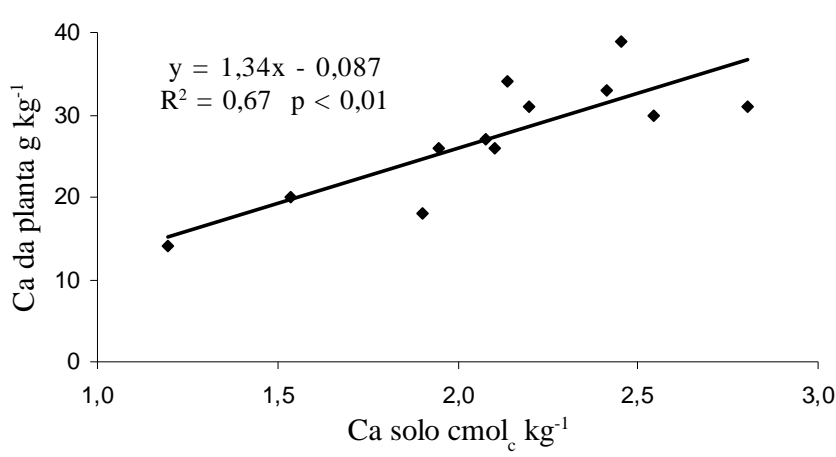

Figura 3. Correlação entre o teor de Ca no solo e o teor de Ca no tecido foliar em 12 áreas de cultivo de batata em Esperança, PB

\section{Deslocamento vertical de $\mathrm{N}$ e bases trocáveis}

Nas áreas com maior entrada de esterco, representadas pelos maiores teores de $\mathrm{P}$ total na camada de $0-20 \mathrm{~cm}$, constataramse aumentos correspondentes nos teores de $\mathrm{N}$ total no solo (Figura 4). O maior teor médio encontrado nas amostras classificadas na faixa 4 foi de $1,1 \mathrm{~g} \mathrm{~kg}^{-1}$ solo na camada de $0-20$ $\mathrm{cm}$. Assumindo-se densidade de solo média de $1,5 \mathrm{~kg} \mathrm{dm}^{-3}$ para esses solos, o teor médio de $\mathrm{N}$ nessa faixa resulta em um estoque de $3300 \mathrm{~kg} \mathrm{ha}^{-1}$ enquanto nas áreas não adubadas o estoque foi, em média, de $975 \mathrm{~kg} \mathrm{ha}^{-1}$. Na camada de 20-40 cm também

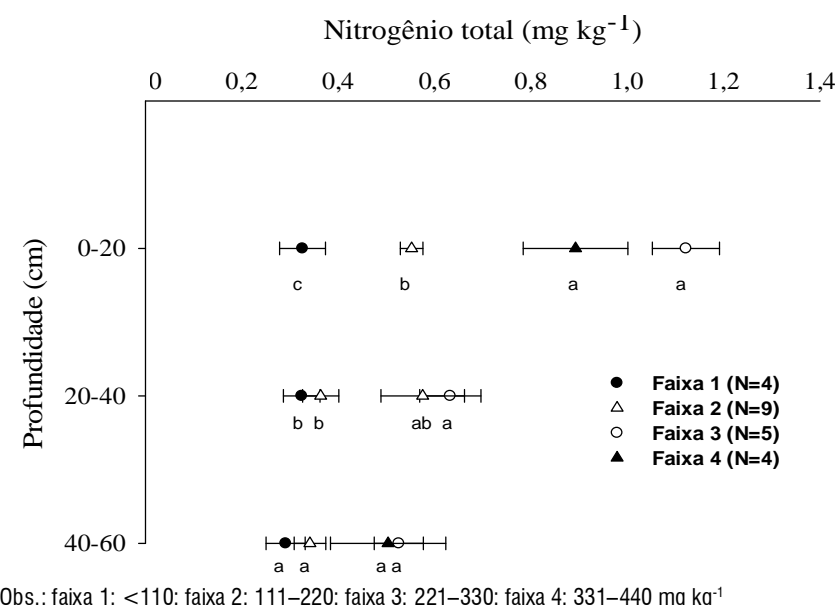

Figura 4. Teor médio e erro padrão de $\mathrm{N}$ total em amostras de solo agrupadas em quatro faixas, de acordo com o teor de $P$ total na camada de $0-20 \mathrm{~cm}$ houve aumento significativo no teor de $\mathrm{N}$ nas áreas de maior entrada de esterco (Faixas 3 e 4 de Ptot) que foi o dobro do encontrado nas áreas da faixa de Ptot menor, sem aplicação ou com pouca aplicação de esterco (Faixas 1 e 2). Na camada mais profunda estudada ainda se mantém o efeito das maiores adubações (Faixas 3 e 4) com esterco, mostrando claramente o deslocamento vertical de Ntot.

$\mathrm{O}$ incremento nos teores de $\mathrm{N}$ no solo na camada superficial (Figura 4), após aplicação de esterco, é basicamente de formas orgânicas (Mitchell \& Tu, 2006), seguindo o padrão de acúmulo de carbono (Galvão et al., 2008), tendo em vista que o N inorgânico é facilmente lixiviado devido à textura do solo, restando apenas o $\mathrm{N}$ associado à matéria orgânica do solo (MOS). A formação de $\mathrm{NO}_{3}$ que ocorre ao longo da transformação dessas estruturas orgânicas (Sommerfeldt et al., 1988), facilita o movimento no perfil junto ao fluxo de água, sobretudo em solos de textura mais grosseira (Menezes \& Salcedo, 2007). Formas orgânicas de nitrogênio também podem se mover no perfil do solo junto aos compostos orgânicos dissolvidos em água, mecanismo aumentado com as práticas que propiciam aumento de $\mathrm{pH}$, como adição de carbonato de cálcio (Oliveira Júnior et al., 2008). A aplicação continuada de esterco nessas áreas de cultivo de batatinha tem promovido acréscimo no $\mathrm{pH}$, devido ao grande aporte de $\mathrm{Ca}$, podendo também estar contribuindo para a lixiviação de $\mathrm{N}$ em formas orgânicas, fato que foi evidenciado para as forma orgânicas de P (Galvão \& Salcedo, 2009)

Nas três camadas de solo estudadas foi notável o aumento nos teores de K extraível por Melich-1, nas áreas com aplicação de esterco; porém, a separação das áreas em faixas de Ptot não permitiu diferenciar claramente o efeito no $\mathrm{K}$ uma vez que as faixas 2, 3 e 4 não diferenciaram estatisticamente (Figura 5). Trabalhando com cama de aviário, Mitchell \& Tu (2006) encontraram, após 10 anos de aplicação de esterco em solo com textura leve, acréscimos nos teores de K, N, Ca e Mg, nos primeiros $20 \mathrm{~cm}$ do perfil.

O potássio adicionado ao solo pelo esterco está todo em forma prontamente disponível, não faz parte de nenhum composto orgânico estável, sendo lavado para o solo facilmente pela água da chuva. No solo, o K é bastante móvel e de fácil lixiviação, haja vista que sua interação com a parte mineral é apenas por ligações eletrostáticas (Ernani et al., 2007). A

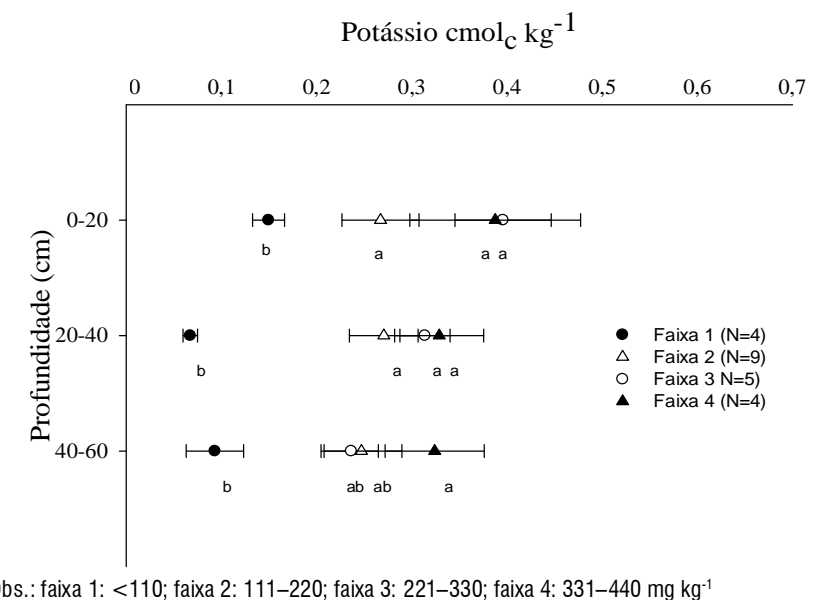

Figura 5. Teor médio e erro padrão de K disponível em amostras de solo agrupadas em quatro faixas, de acordo com o teor de P total na camada de $0-20 \mathrm{~cm}$ 
aplicação de $16 \mathrm{t} \mathrm{ha}^{-1}$ de esterco resulta num aporte de $160 \mathrm{~kg}$ de K (Galvão et al., 2008) e as aplicações seguidas levaram ao aumento de mais de 4 vezes nos teores de $\mathrm{K}$ na camada de 40 $60 \mathrm{~cm}$ de profundidade, considerando-se a faixa 4 , caracterizando um grande movimento de $\mathrm{K}^{+}$no perfil do solo (Figura 5).

O maior acréscimo no K em relação ao nitrogênio na camada de 40-60 cm mesmo sendo o nitrato mais móvel no solo pode ser explicado pela imobilização possível de estar ocorrendo com o N pela biomassa microbiana e pela maior labilidade do $\mathrm{K}$ que do $\mathrm{N}$ no esterco, que retarda e diminui as perdas de $\mathrm{N}$ em relação ao K. Estimativas do balanço anual de nutrientes em batatinha (Galvão et al., 2008) sugeriram que as perdas de $\mathrm{N}$ foram menores que as de $\mathrm{K}$.

De forma semelhante ao observado para o $\mathrm{K}$, nas áreas adubadas com esterco, comparadas com as áreas sem aplicação, o aumento no teor de $\mathrm{Ca}$ e $\mathrm{Mg}$ foi, respectivamente, de 3 e 7 vezes na camada de 0 a $20 \mathrm{~cm}$ e de 4,5 e 4,3 vezes na camada de 40 a $60 \mathrm{~cm}$ (Figuras 6 e 7), indicando a ocorrência de grande movimento dessas bases no perfil do solo. $\mathrm{O}$ aumento no teor de $\mathrm{Ca}$ e $\mathrm{Mg}$ na camada superficial até $20 \mathrm{~cm}$, em solo com aplicação de esterco, foi mostrado em trabalhos com esterco bovino e caprino (Brouwer \& Powell, 1995) e com cama de aviário (Mitchell \& Tu, 2006). Nesses estudos o aumento dos teores nas camadas mais profundas não foi perceptível, provavelmente pelo fato de que os dados são de áreas com 10 ou menos anos de aplicação de esterco.

A aplicação continuada de esterco leva a um aumento do pH (Sharpley \& Moyer, 2000; Eghball, 2000; Galvão et al., 2008), que se relaciona com o movimento de $\mathrm{Ca}^{+2}$ no perfil do solo (Wadt \& Wadt, 1999). Este comportamento é viabilizado pela alta infiltração de água, pois se trata de um solo com muita areia, e pela baixa CTC, que não promove a adsorção desses cátions à fração mineral, o que reduziria a intensidade da translocação (Salcedo et al., 1988). O tempo de aplicação desse resíduo, que em algumas áreas supera os 40 anos, e a dose média de $16 \mathrm{t} \mathrm{ha}^{-1}$, considerada alta em relação à extração das plantas cultivadas, estão determinando este movimento e o acúmulo de bases nessas áreas.

Este uso excessivo de esterco, com base na demanda de $\mathrm{N}$, somente pode encontrar justificativa se mantiver ou promover

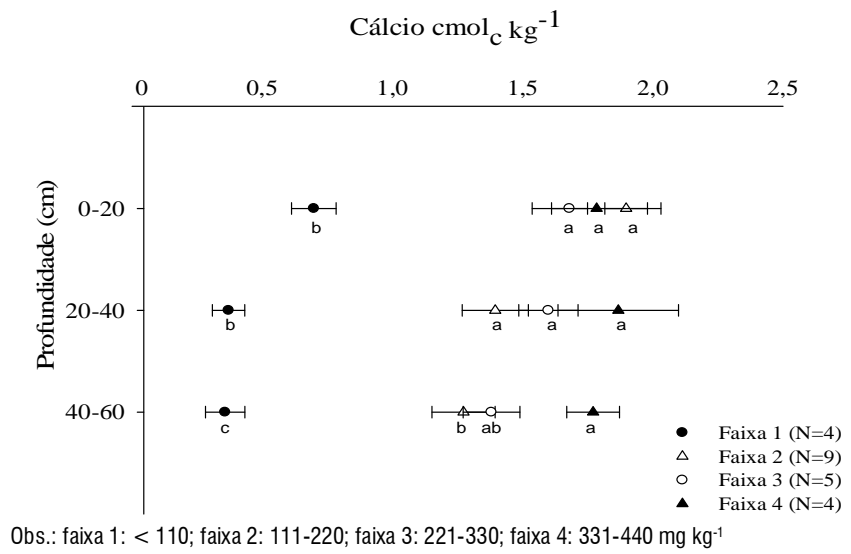

Figura 6. Teor médio e erro padrão de Ca disponível em amostras de solo agrupadas em quatro faixas, de acordo com o teor de P total na camada de $0-20 \mathrm{~cm}$

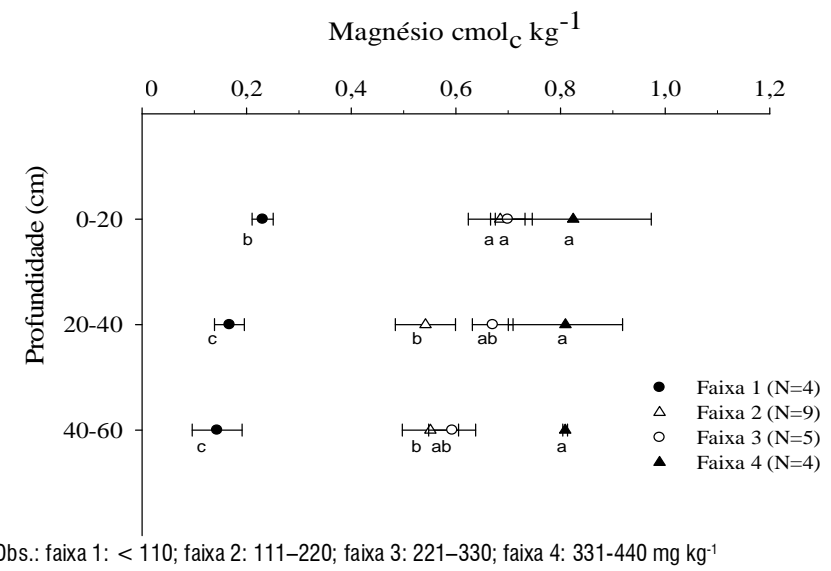

Figura 7. Teor médio e erro padrão de magnésio disponível em amostras de solo agrupadas em quatro faixas, de acordo com o teor de $\mathrm{P}$ total na camada de $0-20 \mathrm{~cm}$

aumento na matéria orgânica do solo, o que seria um efeito benéfico. Por outro lado, as doses que vêm sendo adicionadas com efeito acumulativo ao longo do tempo, determinaram entradas excessivas de outros nutrientes, com consumo de luxo no caso do Ca e provocaram o deslocamento vertical dos mesmos.

\section{ConClusões}

1. Os aumentos em produtividade da batatinha dependem dos teores de Ntot do solo acumulado ao longo dos anos, mas a produção de batata comercial depende da complementação do esterco com fertilizante mineral.

2. A acumulação histórica de nutrientes via aportes de esterco determina aumentos nos teores em profundidade, indicando claramente a lixiviação de bases trocáveis, o que representa prejuízo econômico para os produtores, além de possível risco ambiental.

3. É necessário racionalizar o uso do esterco, pois é um insumo de acesso limitado e que tem custo considerável com base, provavelmente, em suas doses na demanda de $\mathrm{P}$ das culturas ao invés do $\mathrm{N}$, complementando as necessidades de $\mathrm{N}$ com adubação inorgânica.

\section{Agradecimentos}

Ao CNPq, pelo auxílio financeiro (Bolsa de Doutorado e Edital Universal); ao Laboratório de Fertilidade de Solo-DENUFPE, pelo apoio em análises de solo e planta, ao Laboratório de Matéria Orgânica-CCA-UFPB, pelo apoio no preparo de amostras e análise de Ctot, e aos produtores de batatinha de Esperança, PB, por permitirem desenvolver este trabalho em suas áreas de produção.

\section{LITERATURA CITADA}

Akhtar, M.; Mccallister, D. L.; Francis, D. D. Schepers, J. S. Manure source effects on soil phosphorus fractions and their distribuition. Soil Science, v.170, p.187-190, 2005. 
Bayer, C.; Mielnikzuc, J. Dinâmica e função da matéria orgânica. In: Camargo, F. A. O. (ed.) Fundamentos da matéria orgânica do solo: ecossistemas tropicais e subtropicais. Porto Alegre: Gênesis, 1999, p.69-90.

Bremner, J. M.; Mulvaney, C. S. Nitrogen total. In: Page, A. L. (ed.) Methods of soil analysis. Part 2. Madison: American Society of Agronomy, 1982, p.595-624.

Brouwer, J.; Powell, J. M. Soil aspects of nutrient cycling in a manure experiment in Niger. In: Powell, J. M.; FernandezRivera, S.; Williams, T. O.; Renard, C. (ed.). Livestock and sustainable nutrient cycling in mixed farming sytsems of sub-Saharan Africa. Proceedings of an International Conference held in Addis Ababa, Addis Ababa: ILCA, p.211226, 1995.

Cantarutti, R. B.; Barros, N. F.; Novais, R. F.; Martinez, H. E. P. Avaliação da fertilidade do solo e recomendação de fertilizantes. In: Novais, R. F. de; Alvarez, V. V. H.; Barros, N. F.; Fontes, R. L. F; Cantarutti, R. B.; Neves, J. C. L. (org.). Fertilidade do Solo. Viçosa: SBCS, 2007, p.769-850.

Cogo, C. M.; Andriolo, J. L.; Bisognin, D. A.; Godoi, R. S.; Bortolotto, O. C.; Luz, G. L. Relação potássio-nitrogênio para o diagnóstico e manejo nutricional da cultura da batata. Pesquisa Agropecuária Brasileira, v.41, p.1781-1786, 2006.

Eghball, B. Nitrogen mineralization from field-applied beef cattle feedlot manure or compost. Soil Science Society of America Journal, v.64, p.2024-2030, 2000.

EMATER-PB - Empresa de Assistência Técnica e Extensão Rural. Manual de sugestão de adubação para o Estado da Paraíba: primeira aproximação. João Pessoa: EMATER, 1979. 1058p.

EMBRAPA - Empresa Brasileira de Pesquisa Agropecuária. Centro Nacional de Pesquisas de Solos. Manual de Métodos de Análises de Solos. 2.ed. Rio de Janeiro: Embrapa Solos, 1997, 212p.

Erich, M. S.; Fitzgerald, C. B.; Porter, G. A. The effect of organic amendments on phosphorus chemistry in a potato cropping system. Agriculture, Ecosystems and Environment, v.88, p.79-88, 2002.

Ernani, P. R.; Almeida, J. A.; Santos, F. C.; Potássio. In: Novais, R. F.; Alvarez, V. H.; Barros, N. F.; Fontes, R. L.; Cantarutti, R. B.; Neves, J. C. L. (org.). Fertilidade do Solo. 1.ed. Viçosa: SBCS, v. 1, p.551-594, 2007.

Galvão, S. R. S; Salcedo, I. H. Soil Phosphorus Fractions in Sandy Soils Amended with Cattle Manure for Long Periods. Revista Brasileira de Ciência do Solo, v. 33, p.613-622, 2009.

Galvão, S. R. S.; Salcedo, I. H.; Oliveira, F. F. Acumulação de nutrientes em solos arenosos adubados com esterco bovino. Pesquisa Agropecuária Brasileira, v.43, p.99-105, 2008.

Garrido, M. S.; Sampaio, E. V. S. B.; Menezes, R. S. C. Potencial de adubação orgânica com esterco no Nordeste do Brasil. In: Menezes, R. S. C.; Sampaio, E. V. S. B; Salcedo, I. H. (org.). Fertilidade do solo e produção de biomassa no semiárido. Recife: UFPE, 2008, p.123-140.
Griffin, T. S.; Honeycutt, C.W. Using growing degree days to predict nitrogen availability from livestock manures. Soil Science Society of America Journal, v.64, p.1876-1882, 2000.

Menezes, R. S. C.; Salcedo, I. H. Mineralização de N após incorporação de adubos orgânicos em um Neossolo Regolítico cultivado com milho. Revista Brasileira de Engenharia Agrícola e Ambiental, v.11, p.361-367, 2007.

Mitchell, C. C.; Tu, S. Nutrient accumulation and movement from poultry litter. Soil Science Society of America Journal, v.70, p.146-2153, 2006.

Oliveira Júnior, A. C.; Silva, C. A.; Curi, N.; Lima, J. M.; Rangel, O. J. P. Formas e quantidades de carbono em lixiviados de latossolos vermelhos sob influência de calcário e fósforo. Revista Brasileira de Ciência do Solo, v.32, p.1261-1271, 2008.

Sabourin, E.; Silveira, L. M.; Tonneau, J. P.; Sidersky, P. Fertilidade e agricultura familiar no Agreste Paraibano: um estudo sobre o manejo da biomassa. Esperança: Cirad-Terra/ ASPTA, 2000, 59p.

Salcedo, I. H.; Sampaio, E. V. S. B.; Carneiro, I. V. Perdas de N por lixiviação em cana-planta fertilizada com uréia-15N. Pesquisa Agropecuária Brasileira, v.23, p.725-732, 1988.

Sharpley, A. N.; McDowell, R. W.; Kleinnman, J. A. Amounts, forms, and solubility of phosphorus in soils receiving manure. Soil Science Society of America Journal, v.68, p.20482057, 2004.

Sharpley, A. N.; Moyer, B. Phosphorus forms in manure and compost and their release during simulated rainfall. Journal of Environmental Quality, v.29, p.1462-1469, 2000.

Siddique, M. T, Robinson, J.; Alloway, B. J. Phosphorus reactions and leaching potential in soils amended with sewage sludge. Journal Environmental Quality, v.29, p.19311938, 2000.

Silva, T. O.; Menezes, R. S. C.; Tiessen, H.; Sampaio, E. V. S. B.; Salcedo, I. H.; Silveira, L. M. Adubação orgânica da batata com esterco e/ou Crotalaria juncea. I - Produtividade vegetal e estoque de nutrientes no solo em longo prazo. Revista Brasileira de Ciência do Solo, v.31, p.39-49, 2007.

Sommerfeldt, T. G., Chang, C.; Entz, T. Long-term Annual Manure Applications Increase soil organic matter and nitrogen, and decrease carbon to nitrogen ratio. Soil Science Society America Journal, v.52, p. 1668-1672, 1988.

Thomas, R. L.; Sheard, R. W.; Moyer, J. R. Comparison of conventional and automated procedures for nitrogen, phosphorus and potassium analysis of plant material using a single digest. Agronomy Journal, v.59, p.240-243, 1967.

Wadt, P. G. S.; Wadt, L. H. O. Movimento de cátions em amostras de um Latossolo vermelho-amarelo incubadas com duas fontes de cálcio. Scientia Agricola, Suplemento, v.56, p.11571164, 1999. 